\title{
Peningkatan Pengetahuan tentang Narkoba dan HIV/AIDS di Pondok Pesantren Al Hidayah Borowatu, Sukoharjo
}

\author{
Marni \\ Akademi Keperawatan Giri Satria Husada, Wonogiri, Indonesia \\ *Corresponding Author \\ J1. Tentara Pelajar No 01, Giriwono, Wonogiri, Telp/Fax 0273322610 \\ E-mail: marnigsh020@gmail.com \\ Revised: \\ 4 December 2020 \\ Accepted: \\ 15 December 2020 \\ Published: \\ 25 December 2020
}

Received:

26 May 2020

\begin{abstract}
Abstrak
Perilaku sebagian remaja yang mengabaikan nilai-nilai kaidah dan norma yang berlaku di masyarakat menjadi salah satu penyebab maraknya penggunaan narkoba dikalangan generasi muda. Penyalahgunaan narkoba dengan cara disuntikkan bisa berakibat seseorang menderita HIV/AIDS, kondisi ini merupakan kondisi yang sangat berbahaya, mengingat penyakit ini belum bisa disembuhkan. Salah satu faktor penyebab penyalahgunaan narkoba adalah kurangnya pengetahuan tentang narkoba dan HIV/AIDS, santri yang berasal dari berbagai daerah di Indonesia, dengan budaya dan pengetahuan yang bervariasi, dan rata rata pengetahuan masih rendah, untuk itu perlu diberikan pengetahuan pada remaja khususnya santri agar tidak menyalahgunakan narkoba dan menjauhi perilaku beresiko HIV/AIDS seperti penggunaan narkoba suntik dan sex bebas. Kegiatan ini bertujuan untuk meningkatkan pengetahuan santri agar berperilaku sehat dengan menjauhi narkoba dan agar terhindar dari HIV/AIDS. Kegiatan diawali studi pendahuluan, yang dilakukan saat kunjungan pertama dengan membagikan kuesioner. Tahap kedua berkoordinasi dengan pengurus pondok pesantren untuk menentukan waktu pelaksanaan penyuluhan, selanjutnya pelaksaan penyuluhan. Memberikan penyuluhan kesehatan tentang penyalahgunaan narkoba dan pencegahan HIV/AIDS. Ada 3 fase pada proses penyuluhan, yaitu fase orientas/perkenalan, fase kerja dan fase terminasi/evaluasi. Penyuluhan kesehatan telah berhasil dilaksanakan, para santri sangat berantusias dan memahami materi yang telah disampaikan terbukti para santri mampu menjawab pertanyaan yang diajukan oleh pemateri. Penyuluhan kesehatan mampu meningkatkan pengetahuan para santri terkait penyalahgunaan narkoba dan pencegahan HIV/AIDS.dibuktikan sebelum diberikan penyuluhan skor mean 4,95 dan mean setelah diberikan penyuluhan mean kor pengetahuan 6,73 , terjadi peningkatan skor pengetahuan 1,67. Penyuluhan kesehatan kepada para santri terbukti mampu meningkatkan pengetahuan santri tentang penyalahgunaan narkoba dan pencegahan HIV/AIDS yaitu terjadinya mean skor pengetahuan 1,67 .
\end{abstract}

Keywords: HIV/AIDS, Narkoba, Pengetahuan, Pesantren.

\begin{abstract}
The behavior of some adolescents who ignore the norms and norms prevailing in society is one of the causes of rampant drug use among the younger generation. Drug abuse by injection can result in a person suffering from HIV / AIDS, this condition is a very dangerous condition, considering that this disease cannot be cured. One of the factors causing drug abuse is a lack of knowledge about drugs and HIV / AIDS, therefore it is necessary to provide knowledge to adolescents, especially students, so that they do not abuse drugs and stay away from HIV / AIDS risk behaviors such as injecting drug use and free sex. This activity is aimed to increase the knowledge of students to behave in a healthy
\end{abstract}




\begin{abstract}
manner by avoiding drugs and avoiding HIV / AIDS. It was done by providing health education about drug abuse and HIV/AIDS prevention. There are 3 phases in the counseling process, namely the orientation phase / introduction, the work phase and the termination / evaluation phase. It was found that health education has been successfully carried out, the students are very enthusiastic and understand the material that has been delivered is proven to be able to answer questions raised by the speakers. Health education can increase the knowledge of students related to drug abuse and prevention of HIV / AIDS. Health education to students is proven to increase students' knowledge about drug abuse and HIV / AIDS prevention.
\end{abstract}

Keywords: Drugs; HIV / AIDS; Islamic Boarding Schools; Knowledge.

\title{
PENDAHULUAN
}

Pondok pesantren merupakan lembaga pendidikan yang berfokus pada pendidikan agama yang sangat berperan dalam meningkatkan pengembangan sumberdaya (Di et al., 2018). Pesantren merupakan bentuk lembaga pendidikan yang menjadi ujung tombak meningkatkan derajat kesehatan masyarakat khususnya para santri dengan mengedepankan upaya preventif dan promotif (Purwaningsih et al., 2019). Harapannya, santri, para pengurus pondok pesantren, ustadz dan ustadzah serta pemimpin tidak hanya ahli dalam pengembangan moral dan spiritual para santri, namun ahli juga dalam pengembangan kesehatan, dengan menjadi motivator dan innovator dalam meningkatkan kesehatan para santri, dan semua pengurus yang ada dalam pondok pesantren tersebut (Di et al., 2018). Pada study pendahuluan didapatkan data, para santri masih banyak belum mengetahui tentang bahaya narkoba serta HIV/AIDS. Para santri yang sebagian besar berusia remaja, berasal dari berbagai daerah/pulau di Indonesia, memiliki budaya bervariasi dan sangat beresiko terhadap perilaku merokok yang merupakan pintu masuknya penyalahgunaan narkoba, penelitian yang telah dilakukan sebelumnya oleh Astuti menyatakan bahwa merokok adalah pintu masuknya penyalahgunaan narkoba jenis ganja (Astuti, 2016). Faktor-faktor yang menyebabkan penyalahgunaan narkoba adalah faktor internal dan eksternal. Faktor internalnya adalah faktor yang berasal dari diri seseorang yang terdiri dari faktor kepribadian, faktor keluarga serta faktor ekonomi. Sedangkan faktor eksternalnya adalah faktor pergaulan dan faktor sosial/masyarakat (Simangunsong, 2015). Salah satu faktor yang mempengaruhi penyalahgunaan narkoba pada remaja adalah pengetahuan remaja tentang narkoba dan peran orang tua, pada penelitian tersebut pengetahuan responden cukup, responden belum pernah mendapat penyuluhan tentang narkoba di sekolahnya (Ratnasari, 2015).

Penelitian yang telah dilakukan di SMKN 1 Bangkinang mengatakan bahwa sebagian besar siswa kelas X dan XI sebanyak 63,2 \% mempunyai pengetahuan yang kurang tentang narkoba (Syahrial, 2015). Narkoba kepanjangan dari narkotika dan obat-obat berbahaya (psikotropika) merupakan obat yang digunakan dalam bidang pengobatan untuk mengurangi rasa sakit, namun disalahgunakan manusia sebagai penenang dan penghibur apabila seseorang tersebut banyak masalah (Anhari, 2012). Selain itu, pemakaian narkoba juga bisa memberikan pengaruh yang berat seperti pingsan, mabuk, bahkan meninggal (Istiadi, 2012). Pemakaian narkoba suntik bisa mengakibatkan pengguna tersebut tertular penyakit HIV/AIDS (Marni et al., 2018). Perubahan fisik yang terjadi pada pengguna narkoba adalah kalau berjalan sempoyongan, bicara pelo, mengantuk, acuh tak acuh, agresif, curiga. Orang yang over dosis bisa terjadi sesak napas, denyut jantung dan nadi lambat, kulit teraba dingin, napas lambat/berhenti, meninggal. Tanda-tanda pengguna narkoba yang sakaw adalah mata dan hidung berair, menguap dan mengantuk terus menerus, badan terasa sakit seluruh tubuh, takut air dan malas mandi, kejang dan kesadaran menurun (Istiadi, 2012). Tidak hanya remaja yang menggunakan narkoba yang merasakan kerugian penggunaan narkoba, namun para orang tua yang memiliki anak remaja yang menggunakan narkoba mempunyai pengalaman yang sangat 
memprihatinkan, orang tua tersebut sangat berduka, berkepanjangan dan berulang. Tentu hal ini harus segera diatasi, karena tidak hanya remaja saja yang rugi, namun para orang tua pun akhirnya merasakan stigma yang tidak baik oleh masyarakat (Ritanti et al., 2017).

Apalagi saat ini banyak perilaku sebagian remaja yang mengabaikan nilai-nilai kaidah dan norma yang berlaku di masyarakat menjadi salah satu penyebab maraknya penggunaan narkoba dikalangan generasi muda (Amanda et al., 2018). Penelitian yang telah dilakukan sebelumnya mengatakan bahwa perilaku beresiko tertular HIV/AIDS dan penggunaan narkoba suntik dimulai saat remaja usia 13-14 tahun (Marni \& Ratnasari, 2019). Penyalahgunaan narkoba dengan cara disuntikkan bisa berakibat seseorang menderita HIV/AIDS, kondisi ini merupakan kondisi yang sangat berbahaya, mengingat penyakit ini belum bisa disembuhkan, hanya bisa dikontrol dan meningkatkan imunitas untuk bertahan hidup agar lebih lama dan tetap bisa produktif.

Berdasarkan latar belakang diatas perlu keterlibatan perguruan tinggi untuk melakukan pencegahan terhadap penyalahgunaan narkoba dan HIV/AIDS pada para remaja, termasuk para santri yang berusia remaja. Untuk itu kami selaku lembaga pendidikan bidang kesehatan bermaksud meningkatkan pengetahuan santri agar berperilaku sehat dengan menjauhi narkoba dan agar terhindar dari HIV/AIDS (Yusnita et al., 2015), dengan cara memberikan penyuluhan tentang dan cara pencegahan bahaya narkoba dan HIV/AIDS.

\section{METODE}

Tahapan Pengabdian Masyarakat ini diawai dengan studi pendahuluan dengan cara ketua pengabdian mengunjungi pondok pesantren untuk bertemu dengan pengurus pondok pesantren dan santri terkait budaya dan pengetahuan santri. Pada saat kunjunga studi pendahuluan, ketua pengabdian membagikan kuesioner berisi tentang pengetahuan HIV/AIDS dan Narkoba. Jumlah Soal dalam kesioner tersebut adalah 41 untuk pengetahuan tentang HIV/AIDS, dan 26 soal untuk Narkoba. Setelah menngerjakan kuesioner dikumpulkan dan dianalisis. Ketua pengabdian dan pengurus menentukan waktu yang tepat untuk pelaksanaan penyuluhan tentang narkoba dan HIV/AIDS untuk meningkatkan pengetahuan agar para santri melaksanakan apa yang diajarkan dalam penyuluhan tersebut, Indikator keberhasilan dalam pelaksanaan kegiatan pengabdian masyarakat ini adalah terjadinya peningkatan pengetahuan tentang narkoba dan HIV/AIDS dengan peningkatan skor pengetahuan sebelum diberikan penyuluhan, dan terjadi peningkatan seelah diberi penyuluhan. Pemberian kuesioner diberikan $2 \mathrm{x}$, yaitu sebelum dan setelah penyuluhan.

Selanjtnya, kedtua pengabdian memberikan penyuluhan kesehatan tentang bahaya dan cara pencegahan penyalahgunaan narkoba dan HIV/AIDS. Khalayak sasaran pada kegiatan pengabdian ini adalah para santri laki-laki yang berjumlah 22 orang dan perempuan yang berjumlah 11 orang di Pondok Pesantren Al Hidayah Borowatu. Teknik pengambilan dengan total sampiling,yang berjumlah 33 santri. Kegiatan penyuluhan bertempat di rumah warga masyarakat Borowatu, pada bulan Agustus 2019. Penyuluhan Kesehatan dilakukan dengan metode ceramah, dan diskusi (Wardani et al., 2019). Metode ceramah dilakukan dengan memberikan materi tentang bahaya narkoba dan HIV/AIDS, cara mencegahnya kepada para santri laki-laki dan perempuan. Media yang digunakan adalah LCD dan Laptop, peserta dibagi dalam dua kelompok yaitu kelompok santri laki-laki dan kelompok santri perempuan, yang dibatasi dengan tirai, agar santri laki -laki dan perempuan tidak saling memandang.

Ada 3 fase dalam kegiatan penyuluhan kesehatan ini, yaitu fase perkenalan, fase kerja/penyuluhann dan fase terminasi/evaluasi (Ratnasari, 2019). Pada fase perkenalan disitu tim pengabdian mengadakan perkenalan dengan para peserta pengabdian, menjelaskan tujuan kegiatan, memvalidasi dan menanyakan kesiapan peserta. Fase kerja dimulai dengan memberikan beberapa pertanyaan terkait bahaya dan ara pencegahan narkoba, setelah itu 
masuk kegiatan inti dengan memberikan penyuluhan kesehatan tentang bahaya narkoba dan HIV/AIDS serta penanggulangannya dengan metode ceramah, tanya jawab dan diskusi. Peserta sangat antusias dalam sesi ini, tim pengabdiaan juga memberikan ice breaking demontrasi dan simulasi mencuci tangan 5 benar 5 moment agar peserta selalu semangat dan senang dalam mengikuti kegiatan. Tim Pengabdian juga memberi kesempatan kepada peserta pengadian untuk bertanya jawab dan berdiskusi mengenai narkoba. Para peserta sangat antusias dalam mengikuti kegiatan pengabdian ini.

Fase terakhir dalam kegiata ini adalah tahap terminasi/ evaluasi. Tim pengabdian mengadakan evaluasi dengan menanyakan perasaan peserta pengabdian, bagaimana setelah diberikan penyuluhan, apakah sudah memahami, dan evaluasi obyektif dengan menanyakan kembali materi penyuluhan yang telah disampaikan dengan pemberian kuesioner dengan pertanyaan yang sama seperti saat pertama kali diberi kuesioner. Setelah kuesioner terkumpul dilakukan analisis terhadap skor pengetahuan tentang narkoba dan HIV/AIDS, nilai mean sebelum dan sesudah penyuluhan, dan nilai mean peningkatan skor setelah diberi penyuluhan.

\section{HASIL DAN PEMBAHASAN}

\section{Gambaran Lokasi Pengabdian}

Desa Ngasinan merupakan desa di kecamatan Bulu, Kabupaten Sukoharjo, Propinsi Jawa Tengah, Indonesia. Secara geografis desa ini terletak di bagian selatan dari Provinsi Jawa Tengah. Sebagian besar wilayah datar, dan sebagian kecil perbukitan seperti Kampung Mloyo, Gampingan dan Pager Gunung, terbagi menjadi 11 Rukun Warga (RW) dan 30 Rukun Tetangga (RT), dan dibagi menjadi beberapa kampung yaitu Ngasinan, Mloyo, Gampingan, Kedung Batang, Kedung Batok, Pengkol, Borowatu, Sidodadi, Sidomulyo, Weko, Pager Gunung, Kapulawang, Pundung Sari, dan Kebo Kuning. Batas wilayah Desa Ngasinan bagian timur berbatasan dengan desa Karangasem, bagian selatan berbatasan dengan desa Bulu, bagian barat dengan Desa Lengking dan bagian utara berbatasan dengan Alur Sungai Bengawan Solo (civitasbook.com (Ensiklopedia), matak-island.kelas-karyawan.co.id, 2019). Desa Ngasinan mempunyai luas wilayah 3,79 KM, dengan Jumlah penduduk di desa Ngasinan 5682 orang, sebagian besar penduduk Desa Ngasinan pekerja boro yang mengais rejeki di kota-kota besar seperti Jakarta, Bandung, Surabaya, dan luar pulau Jawa, sebagian kecil bekerja sebagai petani, tukang kayu, batu, dan instansi pemerintah baik negeri maupun swasta.

Di Desa Borowatu terdapat pondok pesantren yang bernama Pondok Pesantren Al Hidayah Borowatu. Lokasi pondok pesantren di Dukuh Borowatu, RT 01 RW 04, Desa Ngasinan Kecamatan Bulu, Sukoharjo (Humas Polda, 2019). Pondok Pesantren tersebut berdiri atas inisiatif warga karena ada warga Borowatu yang telah lulus dalam menuntut ilmu di pondok pesantren, supaya lulusan pondok pesantren tersebut bisa mengajarkan ilmu agama yang telah diperoleh kepada orang lain dan masyarakat Borowatu dan sekitarnya, maka warga Borowatu berinisiatif untuk mendirikan Pondok Pesantren, yang dimulai dengan iuran untuk membeli tanah secara gotong royong untuk untuk asrama putra yang berlokasi disebelah barat masjid. Santri yang menempuh pendidikan di Pondok Pesantren Al Hidayah Borowatu berasal dari berbagai daerah, dari masyarakat Borowatu, daerah sekitar seperti Lengking, Ngasinan, Bulu, Sukoharjo, Klaten, Solo, Yogyakarta, sampai luar Pulau Jawa, misalnya Sumatra, Nias, Riau, Flores, dan Palembang. Mereka memperoleh informasi tentang keberadaan Pondok Pesantren tersebut dari Ustadz dan Ustadzah yang mengajar di Pondok Pesantren tersebut. Saat ini jumlah santri laki - laki ada 22 santriwan dan 11 santriwati, usia berkisar dari 6 tahun sampai dengan 20 tahunan, saat ini ada satu mahasiswa yang menjadi santriwati di Pondok Pesantren tersebut. Sedangkan santri yang lain fokus belajar agama di Pondok Pesantren. Pondok pesantren merupakan lembaga pendidikan yang berfokus pada pendidikan agama yang sangat berperan dalam meningkatkan pengembangan sumberdaya (Di et al., 2018). 


\section{Pengetahuan tentang Narkoba dan HIV/AIDS}

Studi pendahuluan dilaksanakan di awal bulan Agustus, didapatkan pengetahuan para santri terkait penyalahgunaan narkoba dan pencegahan HIV/AIDS sebelum diberikan penyuluhan skor pengetahuan dengan nilai mean 4,95. Setelah waktu yang disepakati tiba, dilaksanakan penyuluhan kesehatan.

Penyuluhan kesehatan di laksanakan bertujuan untuk meningkatkan pengetahuan tentang narkoba dan HIV/AIDS pada santri laki-laki dan perempuan di Pondok Pesantren Al Hidayah Borowatu pada bulan agustus 2019 di salah satu rumah warga masyarakat Borowatu. Peserta mengikuti kegiatan penyuluhan kesehatan dengan khidmat, memperhatikan pemberi materi penyuluhan, peserta juga langsung bertanya apabila ada yang mau ditanyakan. Pemberi materi dengan sabar memberikan materi dan memberi kesempatan untuk bertanya terkait narkoba dan HIV/AIDS. Kondisi dan situasi pada saat memberikan materi dapat dilihat pada gambar 1 dibawah ini.

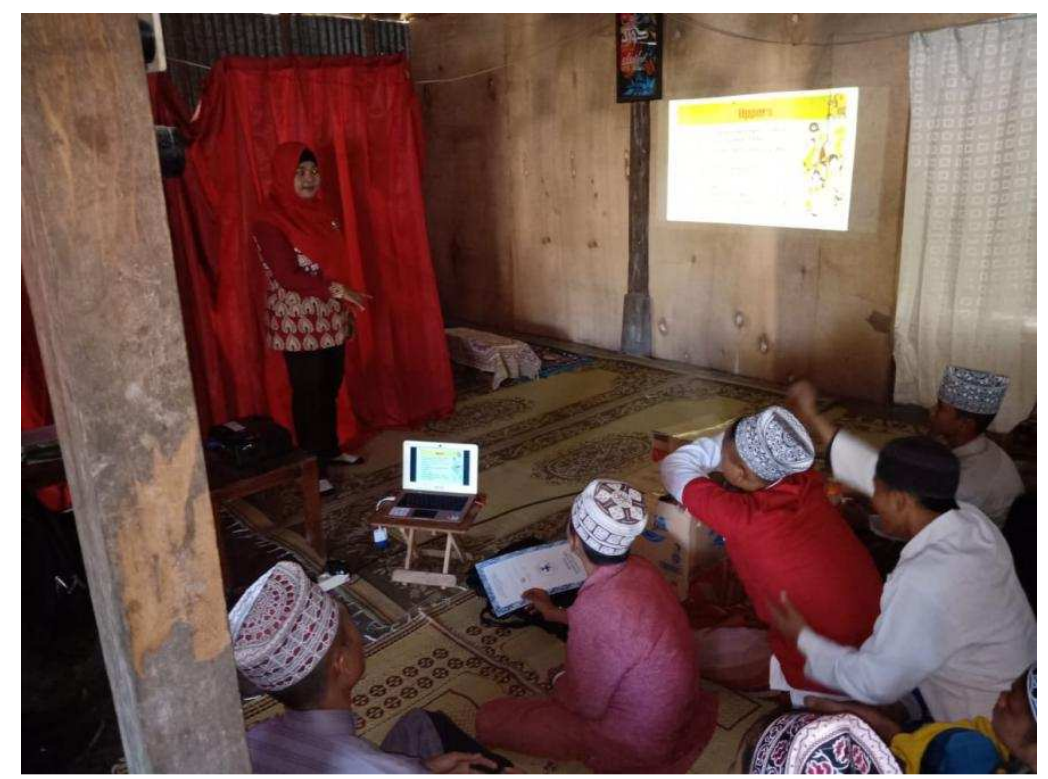

Gambar 1. Pemberian materi penyuluhan tentang bahaya narkoba 


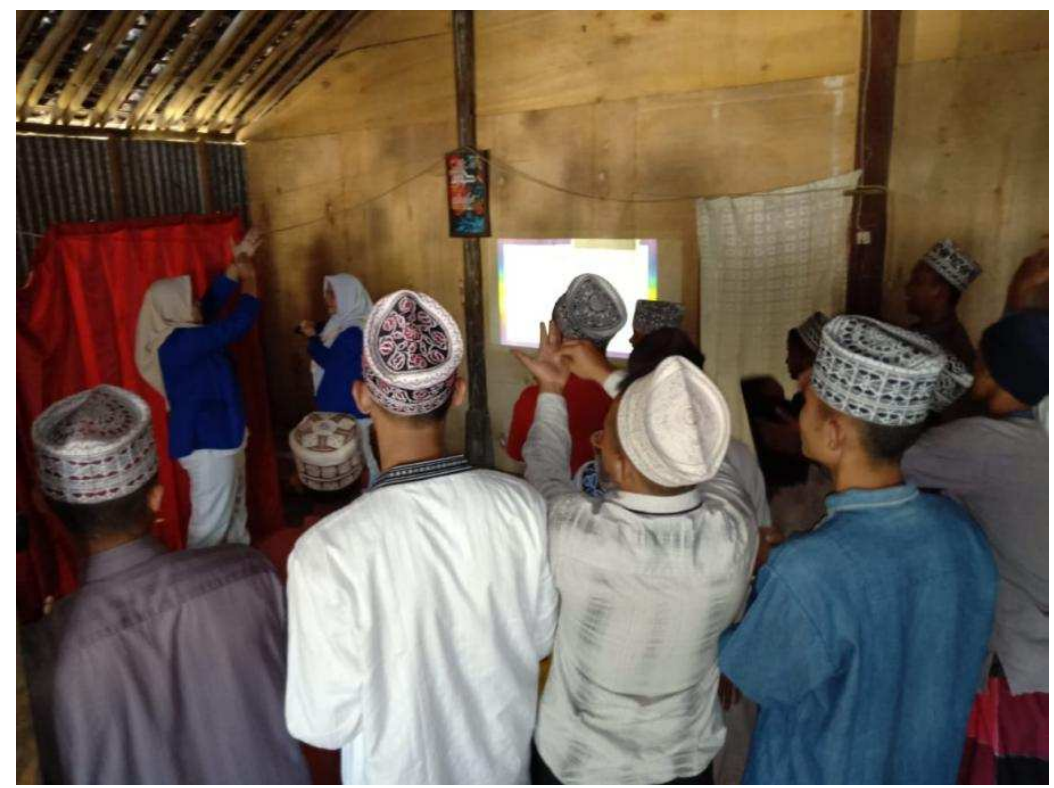

Gambar 2. Ice breaking saat penyuluhan

Untuk menghindari kebosonan dan untuk meningkatkan semangat para peserta pengabdian, tim pengabdian memberikan selingan dengan ice breaking dengan demontrasi dan simulasi cucitangan dengan nyanyian, sehingga para peserta semakin semangat, situasi dan kondisi saat ice breaking dapat dilihat di gambar 2 .

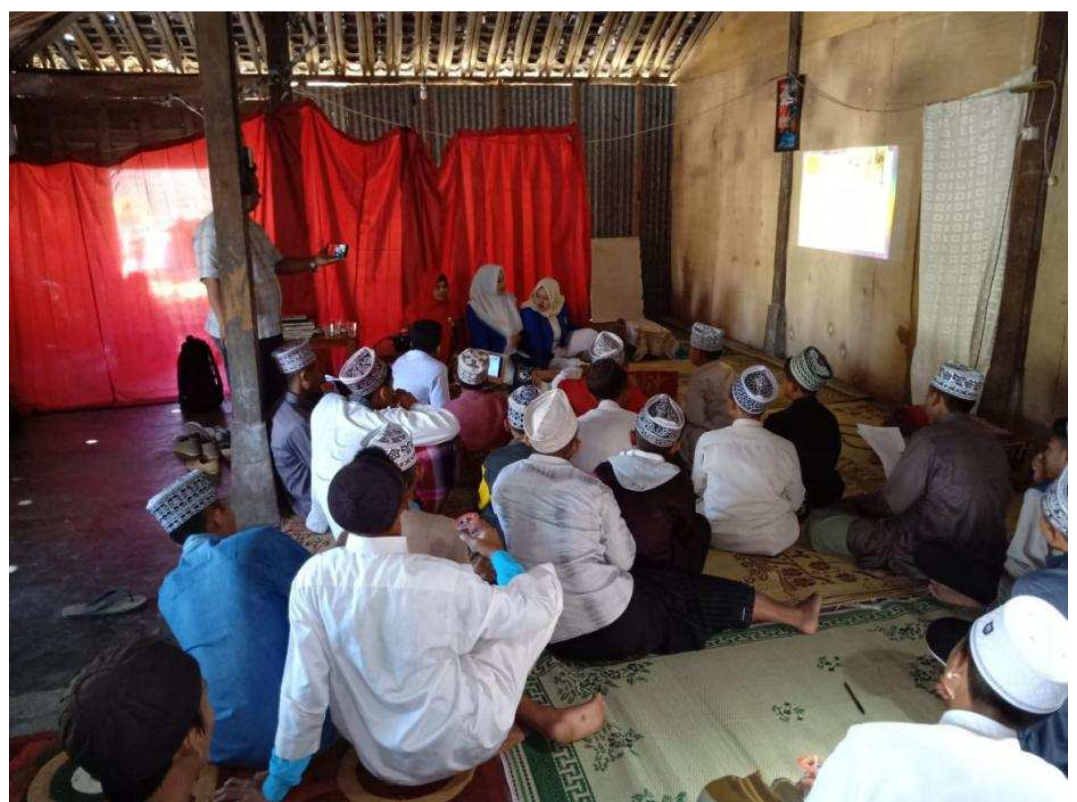

Gambar 3. Peserta berdiskusi dengan tim pengabdian

Gambar 3 menjelaskan kondisi saat diskusi berlangsung antara peserta pengabdian dengan tim pengabdian. Peserta bertanya dan mendiskusikan hal yang tekait dengan rokok, narkoba dan HIV/AIDS. Peserta terliat antusias dalam mengikuti sesi tanya jawab dan diskusi ini.

Para peserta yang rata-rata masih berusia remaja 13 sd 15 tahun adalah suai dimana banyak yang mencoba untuk memulai merokok, tentu hal ini sangat beresiko sebagai pintu 
masuknya penyalahgunaan narkoba, seperti penelitian yang telah dilakukan sebelumnya bahwa usia umur 13 tahun adalah umur pertama kali merokok dan usia umur 15 tahun adalah umur dimana rata rata awal menggunakan ganja (Astuti, 2016). Tentu hal ini sangat mengkhawatirkan. Dengan memberikan penyuluhan kepada para santri, maka pengetahuan santri tentang narkoba dan HIV/AIDS menjadi bertambah, yang dibuktikan skor pengatahuan nilai mean 6,73, terjadi peningkatan skor pengetahuan 1,67. Dengan bertambahnya skor pengetahuan tersebut, diharapkan terjadi perubahan perilaku dari perilaku yang kurang baik menjadi perilaku yang baik dengan menjauhi penyalahgunaan narkoba, dan mencegah terjadinya penyakit HIV/AIDS pada para santri. Pengetahuan merupakan salah satu faktor predisposisi terjadinya perubahan perilaku, sehingga untuk mengubah perilaku yang baik dengan menjauhi pemakaian narkoba, maka seseorang harus diberi pengetahuan (Zulaikhah et al., 2019). Saat dilakukan evaluasi pada peserta, peserta/para santri mengatakan senang sekali diberi penyuluhan kesehatan seperti ini, para santri mengatakan sering sering saja diberi penyuluhan kesehatan, agar semua santri sehat sehingga bisa fokus belajar dan berperilaku sehat dengan tidak merokok, menjauhi narkoba dan tindakan yang bisa menyebabkan HIV/AIDS seperti penyalahgunaan narkoba suntik atau berperilaku sex bebas. Saat pemberi materi menanyakan bagaimana cara mencegah penyalahgunaan narkoba dan HIV/AIDS, peserta bisa menjawab dengan lancar tanpa melihat catatan lagi, itu berarti peserta sudah memahami materi yang telah disampaikan tim pengabdian. Peserta bisa menjawab dengan jawaban meningkatkan iman dan tagwa, bahwa penyalahgunaan narkoba dilarang oleh agama, selalu waspada dan memperhatikan teman bergaul, meningkatkan kemampuan mengatasi masalah, meningkatkan kepercayaan diri agar tidak terpengaruh perilaku buruk teman, tidak merokok, menolak pemberian obat oleh selain petugas kesehatan, tidak mencoba minum obat yang direkomendasikan oleh dokter/petugas kesehatan dan tidak minum tidak minum obat sembarangan, tidak menggunakan narkoba suntik, tidak melalukan hubungan sex bebas. Cara menghindari narkoba bisa juga dengan meningkatkan keharmonisan hubungan antar anggota keluarga, memperbanyak kegiatan bermanfaat, memilih pergaulan dan tidak mudah terpengaruh oleh bujukan orang lain/teman sebaya, menghindari rokok dan meningkatkan keimanan dan ketagwaan (Istiadi, 2012).

Pada saat pemateri menanyakan tentang bagaimana cara menghindari narkoba, lebih dari $70 \%$ peserta bisa menjawab dengan benar, ini berarti bahwa penyuluhan kesehatan untuk meningkatkan pengetahuan yang diberikan oleh tim pengabdian telah berhasil mencapai tujuan. Selain bisa menjawab dengan benar, para peserta juga mengatakan akan menjauhi narkoba dengan meningkatkan keimanan dan ketagwaan dengan rajin belajar dipondok pesantren, menjalin hubungan yang baik dengan keluarga dan teman-teman santri, menambah kegiatan disela-sela belajar dengan berolahraga seperti ikut aktif latihan pencak silat dan sebagainya. Hasil ini sesuai dengan penelitian yang telah dilakukan sebelumnya oleh Bakara yang menyatakan bahwa terdapat perbedaan rata-rata nilai pengetahuan siswa tentang HIV/AIDS sebelum dan sesudah diberikan penyuluhan kesehatan (Bakara et al., 2014). Penelitian lain yang juga sejalan dengan kegiatan penyuluhan kesehatan ini adalah penelitian Noorhidayah yang menyatakan bahwa ada hubungan antara pengetahuan, sikap dan sumber informasi dengan upaya pencegahan HIV/AIDS (Noorhidayah et al., 2016). Hasil pengabdian ini berbeda dengan penelitian yang telah dilakukan oleh ratnasari yang menyatakan bahwa tidak ada hubungan pengetahuan dan sikap terhadap pencegahan narkoba (Ratnasari, 2015). Hal ini bisa terjadi karena faktor lain yang lebih dominan pada penelitian tersebut.

\section{KESIMPULAN}

Penyuluhan kesehatan tentang bahaya penyalahgunaan narkoba dan pencegahan HIV/AIDS terbukti bisa meningkatkan pengetahuan para santri tentang penyalahgunaan narkoba dan Pencegahan HIV/AIDS, yaitu terjadinya peningkatan skor pengetahuan dari nilai mean sebelum 
penyuluhan 4,95 dan mean setelah diberikan penyuluhan mean skor pengetahuan 6,73 , terjadi peningkatan skor pengetahuan 1,67. Dengan hasil tersebut diharapkan perilaku para santri menjadi lebih baik dengan menjauhi penyelahgunaan narkoba dan perilaku yang beresiko timbulnya HIV/AIDS. Para santri mampu menjawab dengan benar dan memahami materi yang telah diberikan oleh tim pengabdian. Para santri juga berjanji untuk berperilaku sehat dengan menjauhi penyalahgunaan narkoba dan HIV/AIDS. Hasil ini sesuai dengan beberapa penelitian sebelumnya bahwa penyuluhan terbukti efektif meningkatkan pengetahuan peserta penyuluhan. Rekomendasi untuk lembaga kesehatan setempat untuk menindaklanjuti kegiatan ini agar tercapai tujuan yaitu perilaku sehat dengan menjauhi narkoba dan menjauhi perilaku beresiko tertular HIV/AIDS. Kedepan perlu diadakan penelitian untuk mengetahui faktor penyebab perilaku beresiko tertularnya HIV/AIDS.

\section{UCAPAN TERIMA KASIH}

Terimakasih yang sebesar-besarnya kami ucapkan kepada Ibu Direktur Akper Giri satria Husada Wonogiri yang telah memberikan kesempatan dan memfasilitasi pelaksanaan penyuluhan kesehatan di Pondok Pesantren Al Hidayah Borowatu, Bapak Ustadz Sobari yang telah berperan aktif dalam memberikan kesempatan dan motivasi kepada para santri, sehingga para santri bisa aktif dan bersemangat dalam mengikuti penyuluhan kesehatan, para mahasiswa yang aktif membantu pelaksanaan pengabdian masyarakat, dan para santri yang telah antusias mengikuti kegiatan ini.

\section{DAFTAR PUSTAKA}

Amanda, M. P., Humaedi, S., \& Santoso, M. B. (2018). Penyalahgunaan narkoba di kalangan remaja (Adolescent Substance Abuse). Prosiding Penelitian Dan Pengabdian Kepada Masyarakat, 4(2), 339-345. https://doi.org/10.24198/jppm.v4i2.14392

Anhari, A. (2012). Strategi pencegahan penyalahgunaan narkoba di kalangan remaja [Universitas Sebelas Maret Surakarta]. https://digilib.uns.ac.id/...=/Strategi-PencegahanPenyalahgunaan-Narkoba-di-Kalanga...

Astuti, N. H. (2016). Merokok pintu masuk untuk penyalahgunaan narkoba jenis ganja. ARKESMAS, 1(1), 45-54.

Bakara, D. M., Esmianti, F., \& Wulandari, C. (2014). Pengaruh penyuluhan kesehatan tentang HIV/AIDS terhadap tingkat pengetahuan siswa SMA. Jurnal Kesehatan, V(1), 67-70.

Civitasbook.com (Ensiklopedia), matak-island.kelas-karyawan.co.id, I. wikipedia. or. (2019). Ngasinan, Bulu, Sukoharjo. In Online Encyclopedia, (pp. 2-3). https://id.wikipedia.org/wiki/Ngasinan,_Bulu,_Sukoharjo

Di, P., Wakaf, Y., Pesantren, U. M. I., Syam, N., Gafur, A., \& Hamzah, W. (2018). PKM pengembangan Pos Kesehatan Pesantren Wihdatul Ulum Desa Bontokassi, Kec. Parangloe, Kab. Gowa. 3(1), 48-61.

Humas Polda (Oktober 2018). Polsek Bulu Sukoharjo bakti sosial di Pondok Pesantren Al Hidayah, Jawa Tengah. https://tribratanews.jateng.polri.go.id/2018/10/06/polsek-bulusukoharjo-bakti-sosial-di-pondok-pesantren-al-hidayah/

Istiadi, P. R. (2012). Pemahaman tentang bahaya narkoba dan rokok pada siswa SMAN 1 Kayen Kabupaten Pati. Tesis, Universitas Negeri Semarang. http://lib.unnes.ac.id/19202/

Marni, M., Nurtanti, S., Handayani, S., Ratnasari, N. Y., \& Susanto, T. (2018). The lived 
experience of women with HIV/AIDS: A Qualitative study. International Journal of Caring Sciences, 11(3), 1475-1482.

Marni, \& Ratnasari, N. Y. (2019). Hubungan Perilaku Beresiko Tertular HIV pada Remaja dengan Pengetahuan Pencegahan HIV / AIDS di Wonogiri Correlation Between HIVAIDS Risk Behavior Among Adolescents With HIV / AIDS Prevention Knowledge in Wonogiri. 17(1), 38-45. https://ejournal.stikespku.ac.id/index.php/mpp/article/view/359/248

Noorhidayah, Asrinawaty, \& Perdana. (2016). Hubungan pengetahuan, sikap, dan sumber informasi dengan upaya pencegahan hiv/aids pada remaja komunitas anak jalanan di Banjarmasin. Dinamika Kesehatan, 7(1), 272-282.

Purwaningsih, I., Mualifah, L., \& Maryati, S. (2019). PKM pos kesehatan pesantren (poskestren) di Pondok Pesantren Modern MBS Pleret Bantul Yogyakarta tahun 2018. $1(1), 13-22$.

Ratnasari, N. Y. (2019). Upaya pemberian penyuluhan kesehatan tentang diabetes mellitus dan senam kaki diabetik terhadap pengetahuan dan keterampilan masyarakat desa Kedungringin, Wonogiri. Indonesian Journal of Community Services, 1(1), 105. https://doi.org/10.30659/ijocs.1.1.105-115

Ratnasari, Y. (2015). Hubungan Pengetahuan, Sikap Siswa tentang Bahaya Narkoba dan Peran Keluarga terhadap Uaya Pencegahan Narkoba. Jurnal Kesehatan Masyarakat Indonesia, $10(2)$.

Ritanti, W., W., Asih, I. D., \& Susanto, T. (2017). A phenomenological study of families with drug-using children living in the society. International Journal of Pediatrics and Adolescent Medicine, 4(3), 100-107. https://doi.org/10.1016/j.ijpam.2017.04.001

Simangunsong, J. (2015). Penyalahgunaan narkoba di kalangan remaja (studi kasus pada badan narkotika nasional e-jurnal oleh jimmy simangunsong program studi ilmu sosiologi. http://jurnal.umrah.ac.id/wp-content/uploads/gravity_forms/1ec61c9cb232a03a96d0947c6478e525e/2015/09/E-jurnal-jimmy.pdf (Diakses pada tanggal 12 Desember 2019)

Syahrial. (2015). Pengetahuan Siswa Kelas X dan XI Tentang Narkoba di SMKN 1 Bangkiang Tahun 2015. Jurnal PG-PAUD STKIP Pahlawan Tuanku Tambusai, 1(2), 153-160.

Wardani, O. P., Turahmat, T., Chamalah, E., Azizah, A., Setiana, L. N., Arsanti, M., Maharani, H. R., Basir, M. A., \& Wijayanti, D. (2019). Pelatihan penulisan karya tulis ilmiah bagi guru-guru SD di desa Geneng kabupaten Jepara. Indonesian Journal of Community Services, 1(1), 116. https://doi.org/10.30659/ijocs.1.1.116-125

Yusnita, Y., Widianti, D., \& Dewi, C. (2015). Upaya Penerapan Gizi Seimbang di Pesantren Sebagai Bagian dari Pemberdayaan Poskestren. Prosiding SNaPP, 37-44.

Zulaikhah, S. T., Wibowo, J. W., Fuad, M. U., Noerhidayati, E., Cahyono, E. B., \& Abduh, M. S. (2019). Penerapan PHBS dengan peningkatan pengetahuan dan sikap melalui pendekatan keluarga di Desa Gaji Kabupaten Demak. Indonesian Journal of Community Services, 1(2), 126-133. 